\title{
Savia emergente para una entidad histórica. Iniciativas de Chiara Panciroli en la Universidad de Bolonia
}

Ricard HUERTA. Universitat de València (España). ricard.huerta@uv.es

La profesora Chiara Panciroli ejerce como docente e investigadora en el Departamento de Ciencias de la Educación “Giovanni Maria Bertin” de la Universidad de Bolonia. Estamos hablando de una institución pionera y de prestigio mundial, de hecho, el marco europeo de educación superior lleva precisamente el nombre de esta universidad italiana con relevante calado histórico: el Plan Bolonia. Conocemos las actividades que impulsa Chiara Panciroli desde hace años, especialmente cuando tomó empuje internacional su fomento de la educación patrimonial a través de congresos y publicaciones. Ha sabido unir esfuerzos con los más prestigiosos museos, implicando siempre a los sectores educativos en sus investigaciones y proyectos. Esta docente, que inició su carrera profesional como maestra, ha sabido llevar a cabo todo un proceso de afirmación académica de la educación artística en museos, generando en su país fuertes lazos de unión entre la universidad, las escuelas y los museos (Soto, 2015). A través del "Centro di Ricerca e di Didattica nei Contesti Museali" de la Universidad de Bolonia ha promovido numerosas acciones en favor de la educación en museos, generando así un ambiente muy favorable entre especialistas de la materia, teniendo en cuenta que un país como Italia ejerce liderazgo mundial en aspectos relacionados con las cuestiones patrimoniales y educativas. Con su proyecto "A Scuola con il Patrimonio" ganó el Concurso Nacional "Progetti didattici nei musei, nei siti di interesse archeologico, storico e culturale, o nelle istituzioni culturali e scientifiche", concedido por el MIUR. Entre sus logros y aciertos destaca sin duda la creación y el desarrollo del MOdE Museo Officina dell'Educazione, una apuesta online que está demostrando la gran capacidad que tiene la educación patrimonial cuando se usan adecuadamente las tecnologías. Os animamos a visitar el MOdE http://www.doc.mode.unibo.it puesto que se trata de un entorno educativo elaborado minuciosamente, donde se pueden encontrar una serie de propuestas formativas con un fuerte atractivo visual y conceptual. Además de conseguir un entorno virtual ameno y coherente, el MOdE se convierte, por su acento innovador, en guía de consulta para quienes deseen aventurarse en la didáctica de las artes desde las plataformas virtuales (Mascarell, 2017). 
El MOdE Museo Officina dell'Educazione es sin duda uno de los grandes aciertos de esta profesora universitaria, debido a la visibilidad de esta propuesta, que tiene una decidida proyección internacional. Su trayectoria profesional viene avalada por sus publicaciones (Panciroli 2015, 2016) y por su faceta en tanto que organizadora de encuentros académicos de investigación educativa, como el Congreso Internacional "Un'esperienza al patrimonio è educativa quando... Progetti, linguaggi, strumenti a confronto". Es una firme defensora de la educación patrimonial, algo que demuestra cada vez que defiende a los mediadores culturales y educadores de museos (Vidagañ, 2016). A nosotros nos ha interesado también acercarnos a la vertiente humana de esta mujer. Tenemos que agradecerle su amabilidad y confianza al habernos abierto las puertas de su casa, un espacio íntimo que relata, a través de estanterías repletas de libros, acompañados siempre de numerosas obras de arte, el espíritu indagador y creativo de quien lo habita (Figura 1).

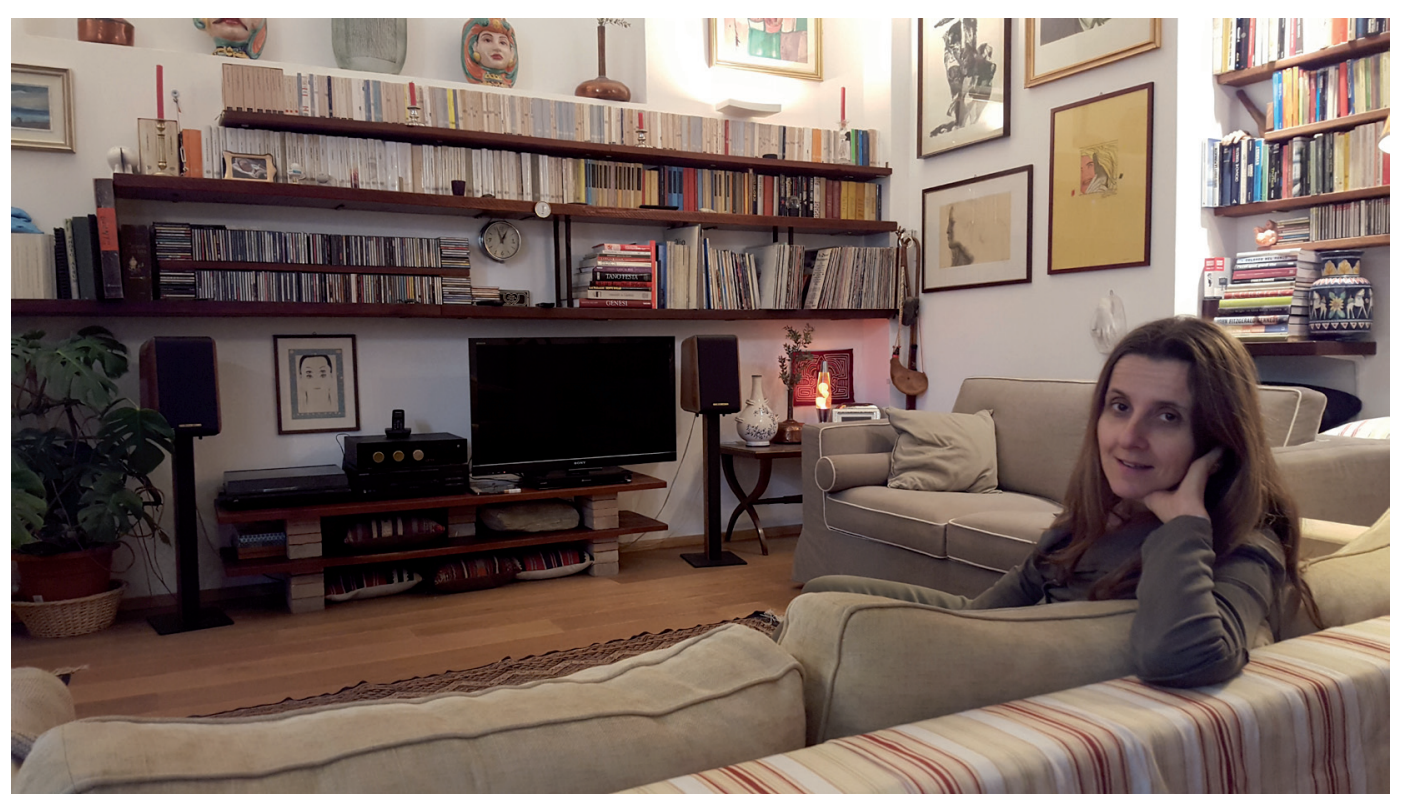

Figura 1. Chiara Panciroli entre libros y obras de arte, en el salón de su casa.

Tu formación inicial fue como maestra; estudiaste para ser docente. ¿Cuándo empezó tu interés por la educación?

Mi interés por la educación nació justo cuando empecé mi carrera como maestra, a través del contacto con los niños en el entorno escolar. Me gustaba ser maestra (en italiano ella usa la expresión mucho más resuelta y enérgica "fare la maestra"), estar con los niños y las niñas, escucharles, para idear, diseñar, realizar y crear con ellos los caminos del conocimiento.

\section{¿Cuándo y por qué diste el paso a la universidad para trabajar como profesora e investigadora?}

Mientras ejercía como maestra (ella usa "facevo la maestra") empecé a estudiar en la Universidad. Indagar en las cuestiones pedagógicas me permitía entender 
mejor muchos aspectos de la práctica educativa. El propio engranaje del estudio universitario me permitía observar a través de un punto de análisis diferente el trabajo del docente (su expresión es "il lavoro dell'insegnante"). Esto me interesaba y me fascinaba. De este modo, en un período corto, hice toda la carrera universitaria, estudiando y trabajando al mismo tiempo. Fue una gran oportunidad para estudiar y trabajar, un intervalo vital e importante para mí. Después de esto decidí dejar la escuela y dedicarme a la investigación y a la formación universitaria. Al principio me ocupé de manera especial de la formación del profesorado ("formazione degli insegnanti" en su italiano original) y de las nuevas tecnologías. Durante las investigaciones del doctorado también empecé a estudiar las prácticas educativas en el museo y qué metodologías didácticas se podían realizar en el seno de estas instituciones. He viajado a varias ciudades europeas para ver y entender la forma como se enseña la educación artística en la escuela y en los museos, incluso con el uso de las tecnologías. Esta ha sido, y sigue siendo, una orientación riquísima y una ruta estimulante.

\section{¿Qué cuestiones te preocupan más de tus obligaciones universitarias?}

Existen muchos compromisos institucionales y administrativos que ocupan buena parte de mi tiempo de trabajo. Esto es algo que en parte me disgusta, puesto que preferiría dedicar más energías a la investigación, a escribir y a viajar para colaborar con otros investigadores en universidades de diferentes países, realizando estancias internacionales de investigación. Me gusta ejercer la enseñanza, la actividad didáctica, pero para ello es necesario renovarse, estudiar nuevos temas, ocuparse de aspectos y estrategias innovadoras de mediación.

Siendo docente de la Universidad de Bolonia, y teniendo en cuenta las
advertencias de Nuccio Ordine (2013) ¿Hacia dónde va la universidad europea?

En los últimos años la universidad italiana está proponiendo políticas que no comparto plenamente. Actualmente se presta mucha atención a validar la calidad de todo el sistema, tratando de conseguir parámetros que a menudo no garantizan efectivamente la calidad, sobre todo porque no tienen en cuenta las necesidades reales y básicas de los estudiantes. Por ejemplo, el nivel general de preparación de los estudiantes ha bajado, a causa de una disminución cultural en general, lo cual está provocado por la lógica de querer atender a un número cada vez mayor de estudiantes, sin abordar seriamente aspectos como la preparación o el estudio. A pesar de ello, el número de usuarios totales de estudiantes universitarios italianos sigue siendo uno de los más bajos de Europa. También la falta de perspectivas de empleo y el miedo difundido por los medios de comunicación acerca de la imposibilidad de encontrar un empleo crea y alimenta entre lajuventud un clima desfavorable para la educación.

Por otro lado, los jóvenes de hoy disponen de una gran cantidad de posibilidades para estudiar en ámbitos de investigación de interés particular, y pueden viajar a otros estados. Esta es sin duda una oportunidad importante para fortalecer las habilidades 
lingüísticas básicas. Igualmente supone reforzar el espíritu de emprendimiento empresarial que, como evidencia la Unión Europea, representa una competencia esencial para conseguir una preparación de perfil alto.

\section{¿Qué podemos aportar desde los países mediterráneos al mundo académico, al mundo de la docencia y al mundo del arte?}

Nuestra cultura mediterránea, tanto en el pasado como en la actualidad, representa un valioso patrimonio, hecho de belleza, de laboriosidad, de curiosidad y de originalidad. La contribución que hacemos desde aquí supone buscar en el pasado, para investigarlo, leerlo y reinterpretarlo, utilizando nuevos lenguajes y nuevas formas de indagar y de construir. Estos aspectos son importantes en el interior del mundo académico: debemos ofrecer modelos formativos fuertes e interesantes que estimulen a los estudiantes para encontrar caminos originales. Por tanto, del mismo modo que debemos proporcionar una formación estimulante e inspiradora a los futuros docentes, hemos de poner en valor la importancia del trabajo educativo que llevan a cabo hacen los propios docentes con niños y jóvenes en las escuelas.

\section{Tu interés por lo artístico viene de lejos. Ya de pequeña pintabas cuadros. ¿Por qué encuentras tan atractivo el arte?}

El arte supone para mí la posibilidad de observar el mundo desde un punto de vista diferente, descubriendo al mismo tiempo aspectos creativos. Representa también la posibilidad de expresarse y de contar de manera profunda aquello que siento. Se convierte incluso en un modo de estar en una situación íntima para encontrarse a sí mismo. De niña me gustaba practicar el arte porque me daba felicidad, y la posibilidad de crear. El arte para mí ha representado siempre un espacio de tranquilidad.

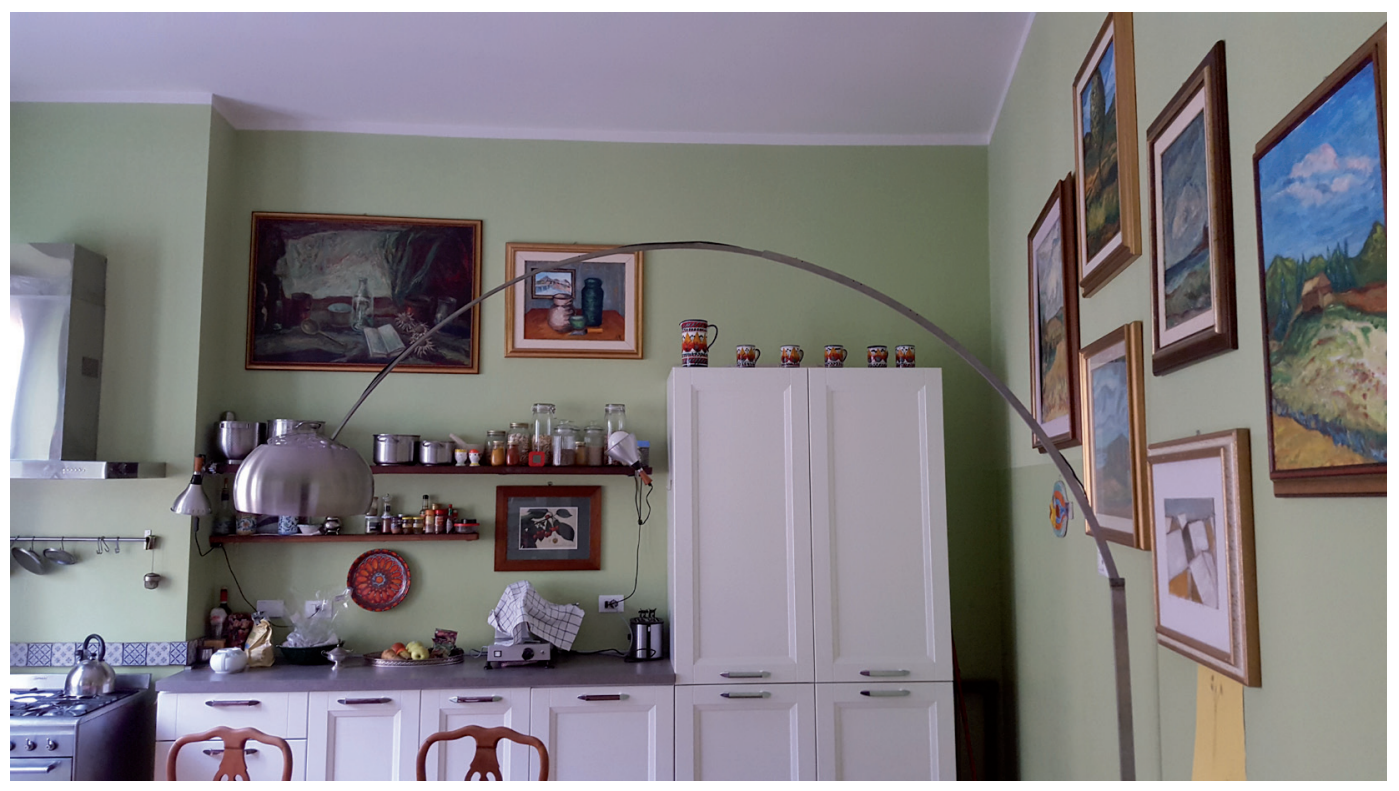

Figura 2. De nuevo obras de arte y objetos de diseño en la cocina de la casa. 


\section{¿Qué es el MOdE?}

El Museo Officina dell'Educazione, MOdE, del Dipartimento di Scienze dell'Educazione dell'Università di Bologna es un espacio virtual de exposiciones que permite compartir temas relacionados con la educación. L'Officina dell'Educazione es un espacio innovador y dinámico, cuyas principales funciones están relacionadas con la exposición, la conservación, la puesta en valor y la difusión de los "objetos" de las Ciencias de la Educación. Este entorno, altamente interactivo, se propone como un laboratorio de investigación con el fin de aprender, de experimentar, interpretar y compartir los testimonios materiales e inmateriales de la cultura educativa. El MOdE, aceptando plenamente las posibilidades que ofrece el uso compartido de redes, permite a todos los visitantes extraer información organizada de una manera flexible y garantizar el aprendizaje independiente. Esto supone realizar itinerarios estructurados y personalizados, participando en una comunidad de práctica, constituida por expertos provenientes de diferentes realidades museísticas y de estudiantes en formación, que indaga sobre temas de educación en museos y de patrimonio cultural. Es un espacio de documentación de buenas prácticas para profesorado de todos los niveles escolares. En la actualidad el MOdE es frecuentado por estudiantes universitarios, profesionales de museos, expertos en arte y en patrimonio cultural, educadores (ella usa la expresión "insegnanti", que elimina el rasgo de género y además incide en el concepto de "enseñanza") y responsables de los servicios educativos.

\section{¿De qué manera está influyendo en nuestras trayectorias vitales el paso hacia el mundo digital?}

Lo digital forma parte de nuestras vidas. Nos ofrece grandes oportunidades y al mismo tiempo limita nuestras vidas. Sin duda, nos lleva a vivir la esfera social de una manera diferente: con más distancia, pero también con una mayor frecuencia. Esto nos lleva a compartir especialmente la vida cotidiana con muchas otras personas, sin profundizar de manera plena sobre la situación.

\section{¿Cómo definirías a los actuales estudiantes de Magisterio?}

Los futuros profesores son estudiantes un poco asustados que parece que no estén del todo convencidos de que van a convertirse en verdaderos maestros. Por este motivo me siento un poco desalentada. En cualquier caso, cuando vienen a clase y se sienten estimulados por el conocimiento, asumen la riqueza de su potencial y enriquecen la clase con preguntas interesantes. Les resultan muy atractivas las tecnologías, que a veces son utilizadas de forma repetitiva por lo que se aburren al saber qué hacer con estas herramientas. ¡Y sin embargo, cuando se les sitúa ante situaciones más complejas, son capaces de hacer búsquedas y productos realmente originales! 


\section{¿Qué modelos pedagógicos actuales te resultan más interesantes?}

Hablar de modelos pedagógicos actuales resulta verdaderamente complejo. Prefiero hablar de metodologías más oportunas y eficaces para lograr objetivos educativos. Entre ellas quiero referirme a las metodologías activas, que van desde Dewey hasta hoy mismo, mediante contribuciones interesantes por parte de diversos estudiosos a nivel internacional, y que se difunden tanto en el interior de la escuela como en otros tantos contextos formativos de aprendizaje.

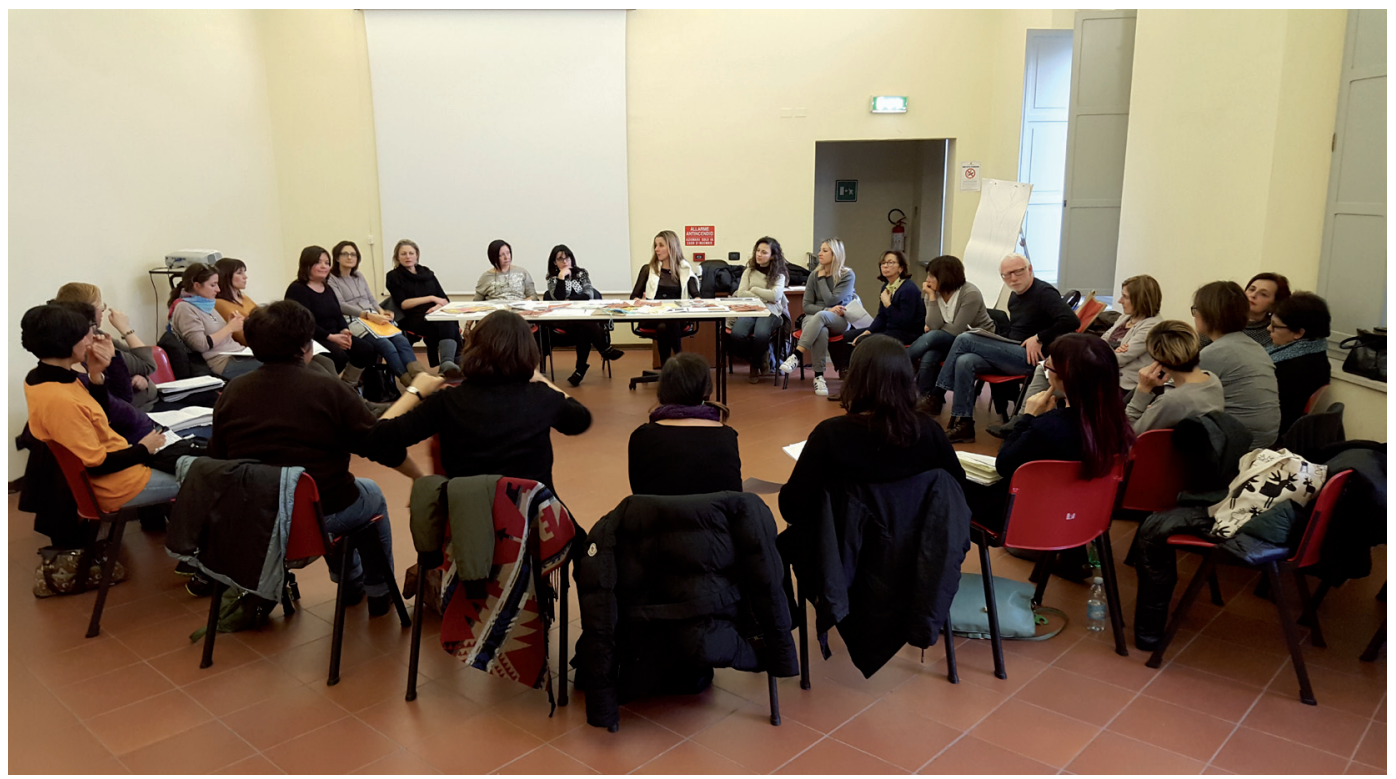

Figura 3. Chiara Panciroli impartiendo un seminario con docentes de Ravenna.

\section{¿Cómo ves el futuro de la educación artística?}

Tal y como sostienen las conclusiones de la Conferencia Internacional de InSEA que tuvo lugar en Lisboa en 2006, "la educación artística es un derecho humano universal en el cual las artes juegan un rol clave en una educación completa que permite el pleno desarrollo del individuo". La importancia que se le reconoce a la educación artística en la formación de cada persona, hace que sea una prioridad actuar en todos los niveles educativos, desde educación infantil hasta educación secundaria.

De hecho, desde la primera infancia la educación artística puede contribuir a la formación de una personalidad creativa, desarrollando en el individuo un tipo de pensamiento, problemático, capaz de adaptarse a su medio ambiente y de encontrar respuestas y soluciones fuertemente personalizadas. Desde hace varios años en Italia y en algunos países europeos se ha reducido el tiempo de la escuela dedicada al arte y esto es realmente un asunto muy serio para asegurar el desarrollo social y la educación. 


\section{¿Qué aconsejarías a los maestros con una trayectoria dilatada sobre los beneficios didácticos del arte?}

Yo les recomendaría que estén siempre pendientes de los conocimientos en sus diversas manifestaciones y en especial a las artes, desde las más tradicionales a las más performativas y contemporáneas. Especialmente se trata de encontrar nuevas estrategias y energías con el fin de involucrar a los niños y jóvenes a participar de forma activa a partir del territorio en el que viven, a través del teatro, las artes visuales, la poesía, el cine y cada evento que ofrezca la oportunidad de comunicarse y expresarse.

\section{¿Crees que el futuro laboral de nuestros estudiantes está en los países del norte?}

Espero que no, pero si la gente joven tiene que viajar y formarse en Europa, también puede de este modo experimentar diferentes actividades de trabajo. Los países del norte no deben ser un escape, sino una oportunidad para la vida profesional.

\section{Referencias bibliográficas}

Mascarell, D. (2017). Les TIC en la formació universitària de mestres. El telèfon mòbil en Didàctica de l'Expressió Plàstica a la Facultat de Magisteri de la Universitat de València. Tesis doctoral: Universitat de València.

Ordine, N. (2013). La utilidad de lo inútil. Barcelona: Acantilado.

Panciroli, Ch. (ed.) (2015). Formare al Patrimonio nella scuola e nei musei. VeronaBolzano: QuiEdit.

Panciroli, Ch. (2016) Le professionalità educative tra scuola e musei: esperienze e metodi nell'arte. Milano: Edizioni Angelo Guerini.

Soto, M. D. (2015). Espacios de inclusión e implicaciones educativas entre escuela, museo y universidad. Análisis desde la investigación-acción. Tesis doctoral: Universitat de València.

Vidagañ. M. (2016). Museos, mediación cultural y artes visuales: perfiles profesionales del ámbito educativo. Tesis doctoral: Universitat de València. 